\title{
Cross-cultural Issues on Organizational Dissent and Humor Orientation
}

\author{
Stephen Croucher ${ }^{1}$, Stephanie Kelly ${ }^{2}$, Hui Chen ${ }^{1}$
}

\author{
${ }^{1}$ Massey University, New Zealand \\ ${ }^{2}$ North Carolina A\&T State University, Greensboro, NC, USA
}

Organizational dissent is the expression of disagreement or contradictory opinions concerning organizational policies and practices (Kassing, 1998). It is an important form of communication because employees can give feedback to organizations regarding discontent and unethical practices. Thus, dissent provides organizations opportunities for improvement and innovation. Managers, however, often fail to recognize and respond to employees' upward dissent. While power differences in organizations stifle communication, humor can be used as a form of dissent and a means to subvert power differences (Holmes \& Marra, 2002). Research has explored organizational dissent in the United States. These results, however, cannot be applied to other contexts, as cultural differences should be considered when exploring communication (McCroskey \& McCroskey, 1988). Thus, this analysis provides the following: First, this analysis provides a theoretical understanding of how humor and dissent relate to one another. Second, this analysis considers this relationship in divergent cultural contexts.

\footnotetext{
Received: May 8, 2018 Revised: Jul 17, 2018 Accepted: Jul 22, 2018 Corresponding author: Stephen Croucher School of Communication, Journalism, and Marketing, Massey University, New Zealand

Tel: +64-021-462-027, E-mail: s.croucher@massey.ac.nz

This is an Open Access article distributed under the terms of the Creative Commons Attribution Non-Commercial License (http://creativecommons.org/licenses/ by-nc/4.0/) which permits unrestricted non-commercial use, distribution, and reproduction in any medium, provided the original work is properly cited. Copyright $(2) 2018$ Korean Association for Business Communication.
}

\section{National Comparisons of Power Distance and Individualism/Collectivism}

Hofstede (1980) identified dimensions of cultural variance. Two dimensions pertinent to dissent are individualism/collectivism (IDV/CDV) and power distance (PDI) (Croucher, Parrott, Zeng, \& Gomez, 2014). Research has shown IDV/CDV and PDI to be significant predictors of dissent. Individuals in more collectivistic cultures, such as Korea, China, and Japan, tend to dissent less than individuals in individualistic cultures, such as the US.

Collectivism emphasizes group-based values such as loyalty, harmony, unity, conformity, and the acceptance of norms, attitudes, and values in an organization as its most important values. Individuals in collectivistic cultures tend to respect and follow traditions and social hierarchy to avoid conflicts with others (Zhang, Lin, Nonaka, \& Beom, 2005), and politeness is emphasized. Many collectivists think disagreeing with others in organizations is undesirable and that they should thus avoid disagreements in dealing with personal relations; they often use an indirect and polite communication style (Hofstede, 1991). Individualists are more likely to use a more direct communicative style.

Hofstede (1997) defined power distance as the extent "to which less powerful members of institutions and organizations within a country expect and accept that power is distributed unequally" (p. 28). In high-power distance structures, leaders are typically more influential and unchallenged. Employees rarely disagree with their bosses and rather exhibit loyalty to or- 
ganizational power structures, while subordinates are more likely to contradict their bosses in low-power distance structures. Croucher et al. (2009) found that individuals in higher-power distance countries are less likely to dissent than individuals in lower power distance countries. The US has been identified as an individualistic and low-power distance country while Japan, China, and Korea have been identified as collectivistic and high-power distance. Although East Asian nations are identified as collectivistic cultures, they have unique characteristics. These nations "should not be treated as a single cultural entity, because each nation developed its own unique Confucian characteristics under the influence of globalization" (p. 113). We use Hofstede's dimensions for theoretical comparisons. We recognize these countries have different economic and political systems, all of which influence an individual's willingness to dissent.

\section{Organizational Dissent}

In Kassing's model, organizational dissent consists of three types of dissent based on channel and audience selection. Articulated dissent is open and direct communication to influential organizational members. Latent dissent is communicating opinions to ineffective audiences (i.e., coworkers) rather than superiors with organizational power. Displaced dissent is expressing criticism to external audiences (i.e., friends, family, and significant others).

Dissent has three aspects. It must be expressed; it involves the discussion of disagreement or contradictory opinions; and it must be about organizational practices, policies, or operations (Kassing, 1997). When a person dissents, the communicative strategy is influenced by a number of factors. Scholars have investigated how those factors may influence employees' decision to express dissent. Furthemore, employees' assessment of how their dissent will be perceived and how likely retaliation will be impacts the decision to express dissent (Kassing, 1997), as expressing dissent has a risk of retaliation. Employees have a relatively clear sense of how dissent will be characterized in their organizations. Therefore, employees must assess the degree to which their dissent will be characterized as constructive or adversarial. In this sense, humor can be one way for individuals to soften potentially adversarial dissent messages (Sollitto \& Meyers, 2015).

\section{Cultural Differences in Expressing Organi- zational Dissent}

There is little work on organizational dissent in non-US contexts or in international settings. Croucher et al. (2009) surveyed individuals in the US and India to study the relationship be- tween dissent and argumentativeness. Argumentativeness and dissent were not positively correlated, and tenure did not relate to dissent. Croucher et al. (2014) also surveyed individuals in Finland, France, Germany, Spain, and the United Kingdom, to confirm the relationship between dissent and workplace freedom of speech (WPFS) and to explore differences in dissent and WPFS between the nations. Results revealed WPFS is not positively correlated with dissent because employment legislation and economic pressures on organizations influence dissent. In particular, nations with more employment legislation had more dissent and WPFS.

As the decision to express dissent is influenced by various factors, it is difficult to predict dissent in different cultures. Moreover, economic and political differences between the US, Japan, China, and Korea could influence the expression of dissent. For example, Employment Protection Legislation (EPL) is an important indicator of the labor market. A higher EPL score indicates more regulations and less flexibility in labor markets. A higher score represents a higher likelihood of perceiving WPFS and dissent because in such economic situations, hiring and firing must be done more judiciously because there are more laws (regulations) protecting workers and companies (Barone, 2001).

Dissent does not take place in a vacuum. Communication exists in political and cultural systems. Regarding cultural systems, research has demonstrated that individuals living in more individualistic cultures are more likely to express upward dissent (Ingwar, 2014). As for political systems, the US and Korea are identified as multiparty systems. Japan is a constitutional monarchy, while China is a one-party system. Political systems shape the public's perceptions of authority and their participation in organizations, which might influence dissent.

\section{Humor}

Humor is "intentional verbal and nonverbal messages which elicit laughter, chuckling, and other forms of spontaneous behavior taken to mean pleasure, delight, and/or surprise in the targeted receiver" (Booth-Butterfield \& Booth-Butterfield, 1991, p. 206). There are various approaches to the study of humor. One approach is biological. From this perspective, every human possesses this characteristic differently, and one will become more humorous than another as one gets older and learns more to develop his/her sense of humor in life. Second, humor can be psychological. People have different interpretations of other's actions as humorous, funny, or offensive, depending on the perceived intention of a speaker (Ojha \& Holmes, 2010). Humor can change the dynamics of experiences. We can use humor to 
feel superior to another person or feel superior as compared to a previous moment. Third, humor is present in all cultures, including organizations (Ojha \& Holmes, 2010).

It is typical to see humor within organizations, where humor "consists of amusing communications that produce positive emotions and cognitions in the individual, group, or organization" (Romero \& Cruthirds, 2006, p. 59). Humor also serves the function of expressing disagreement and conflict without negative consequences since the message is delivered in a playful manner (Martin, Puhlik-Doris, Larsen, Gray, \& Weir, 2003). In the process of using humor to express disagreement, people attempt to control the impressions others form of them when considering potential benefits and harms of those disagreements (Kassing \& Armstrong, 2002). As expressing dissent has a potential risk of retaliation, individuals will assess how their expression of dissent will be perceived and how likely retaliation will be. This assessment impacts the decision to express dissent.

Martin and Sullivan (2013) found nationality affected humor generation/use in social situations. The UK, the US, and Australia all value humor differently and have different tendencies towards using humor. There are also differences in humor expression in collectivistic cultures, like Asian contexts, as humor is culture and context-specific (Lin \& Tan, 2010). Yue (2011) found Chinese people are traditionally ambivalent about humor. Murata (2014) explored humor in business meetings in New Zealand (NZ) and Japanese businesses and found that the instigation of humor in NZ is co-constructed by any member of a meeting while in Japanese meetings, humor is constructed by those with power.

Sollitto and Myers (2015) showed a positive relationship between humorous messages and dissent messages. However, that research line is not about how an individual's humor orientation relates to their tendency to dissent in different cultures. Considering how disagreements are more appreciated in individualistic cultures than in collectivist cultures, individuals in the US and the three East Asian nations might have different propensities for humor. Though the three East Asian cultures all are influenced by Confucianism, they developed their own features influenced by globalization and cultural changes (Zhang et al., 2005).

\section{Conclusion}

Understanding the links between dissent and humor offers a greater understanding of how organizations function. Moreover, exploring this relationship in different cultural settings provides more in-depth understanding of cultural variations in organizations.

\section{References}

Barone, A. (2001). Employment protection legislation: A critical review of the literature. Retrieved from http://jpkc.ojc.zj.cn/ldfx/ UploadFiles/2010928214832623.pdf

Booth-Butterfield, S., \& Booth-Butterfield, M. (1991). Individual differences in the communication of humorous messages. Southern Journal of Communication, 56(3), 205-218.

Croucher, S. M., Braziunaite, R., Homsey, D., Pillai, G., Saxena, J., Saldanha, A., .. . Agarwal, K. (2009). Organizational dissent and argumentativeness: A comparative analysis between American and Indian organizations. Journal of Intercultural Communication Research, 38(3), 175-192.

Croucher, S. M., Parrott, K., Zeng, C., \& Gomez, O. (2014). A cross-cultural analysis of organizational dissent and workplace freedom in five European economies. Communication Studies, 65(3), 298-313.

Hofstede, G. (1980). Culture's consequences: International differences in work related values. Beverly Hills, CA: Sage.

Hofstede, G. (1991). Cultures and organizations: Software of the mind. New York, NY: McGraw-Hill.

Hofstede, G. (1997). Cultures and organizations: Software of the mind (Rev. ed.). New York, NY: McGraw Hill.

Holmes, J., \& Marra, M. (2002). Over the edge? Subversive humor between colleagues and friends. Humor, 15(1), 65-87.

Ingwar, N. I. (2014). Exploring relationships between employees' locus of control, individualism and collectivism orientation, and upward dissent message strategies (Master's thesis). University of Alaska Fairbanks, Fairbanks, AK.

Kassing, J. W. (1997). Articulating, antagonizing, and displacing: A model of employee dissent. Communication Studies, 48(4), 311332.

Kassing, J. W. (1998). Development and validation of the organizational dissent scale. Management Communication Quarterly, 12(2), 183-229.

Kassing, J. W., \& Armstrong, T. A. (2002). Someone's going to hear about this: Examining the association between dissent-triggering events and employees' dissent expression. Management Communication Quarterly, 16(1), 39-65.

Lin, T. T., \& Tan, P. S. W. (2010). How cultural and linguistic pluralism shape humor: Social construction of Singapore's humor industry. Intercultural Communication Studies, 19(1), 60-77.

Martin, G. N., \& Sullivan, E. (2013). Sense of humor across cultures: A comparison of British, Australian and American respondents. North American Journal of Psychology, 15(2), 375-379.

Martin, R. A., Puhlik-Doris, P., Larsen, G., Gray, J., \& Weir, K. (2003). Individual differences in uses of humor and their relation to psychological well-being: Development of the Humor Styles Ques- 
tionnaire. Journal of Research in Personality, 37(1), 48-75.

McCroskey, J. C., \& McCroskey, L. L. (1988). Self-report as an approach to measuring communication competence. Communication Research Reports, 5(2), 108-113.

Murata, K. (2014). An empirical cross-cultural study of humour in business meetings in New Zealand and Japan. Journal of Pragmatics, 60, 251-265.

Ojha, A. K., \& Holmes, T. L. (2010). Don't tease me, I'm working: Examining humor in a Midwestern organization using ethnography of communication. The Qualitative Report, 15(2), 279-300.

Romero, E. J., \& Cruthirds, K. W. (2006). The use of humor in the workplace. The Academy of Management Perspectives, 20(2), 58-69. Sollitto, M., \& Myers, S. A. (2015). Peer coworker relationships: Influences on the expression of lateral dissent. Communication Reports, 28(1), 36-47.

Yue, X. D. (2011). The Chinese ambivalence to humor: Views from undergraduates in Hong Kong and China. Humor-International Journal of Humor Research, 24(2), 463-480.

Zhang, Y. B., Lin, M. C., Nonaka, A., \& Beom, K. (2005). Harmony, hierarchy and conservatism: A cross-cultural comparison of Confucian values in China, Korea, Japan, and Taiwan. Communication Research Reports, 22(2), 107-115. 